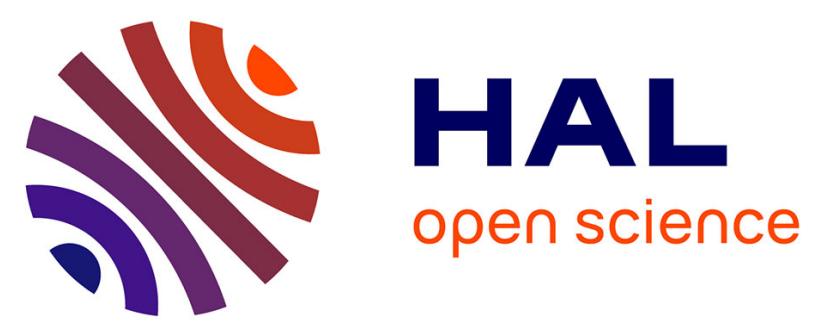

\title{
Near-Infrared Electrochemiluminescence in Water through Regioselective Sulfonation of Diaza [4] and [6]helicene Dyes
}

Haidong Li, Romain Duwald, Simon Pascal, Silvia Voci, Céline Besnard, Johann Bosson, Laurent Bouffier, Jérôme Lacour, Neso Sojic

\section{To cite this version:}

Haidong Li, Romain Duwald, Simon Pascal, Silvia Voci, Céline Besnard, et al.. Near-Infrared Electrochemiluminescence in Water through Regioselective Sulfonation of Diaza [4] and [6] helicene Dyes. Chemical Communications, 2020, 10.1039/D0CC04156D . hal-02907463

\section{HAL Id: hal-02907463 \\ https://hal.science/hal-02907463}

Submitted on 11 Dec 2020

HAL is a multi-disciplinary open access archive for the deposit and dissemination of scientific research documents, whether they are published or not. The documents may come from teaching and research institutions in France or abroad, or from public or private research centers.
L'archive ouverte pluridisciplinaire HAL, est destinée au dépôt et à la diffusion de documents scientifiques de niveau recherche, publiés ou non, émanant des établissements d'enseignement et de recherche français ou étrangers, des laboratoires publics ou privés. 


\section{Near-Infrared Electrochemiluminescence in Water through Regioselective Sulfonation of Diaza [4] and [6]helicene Dyes}

Haidong Li, ${ }^{a}$ Romain Duwald, ${ }^{\mathrm{b}}$ Simon Pascal, ${ }^{\mathrm{b}}$ Silvia Voci, ${ }^{\mathrm{a}}$ Céline Besnard, ${ }^{\mathrm{c}}$ Johann Bosson, ${ }^{\mathrm{b}}$ Laurent Bouffier, ${ }^{a}$ Jérôme Lacour, ${ }^{* b}$ and Neso Sojic*a

a. Univ. Bordeaux, Bordeaux INP, CNRS, Institut des Sciences Moléculaires, UMR 5255. 33607 Pessac, France. E-mail: neso.sojic@enscbp.fr

b. Department of Organic Chemistry. University of Geneva. Quai Ernest Ansermet 30, 1211 Geneva 4, Switzerland. E-mail: jerome.lacour@unige.ch

c. Laboratoire de Cristallographie, University of Geneva, Quai Ernest Ansermet 24, 1211 Geneva 4, Switzerland

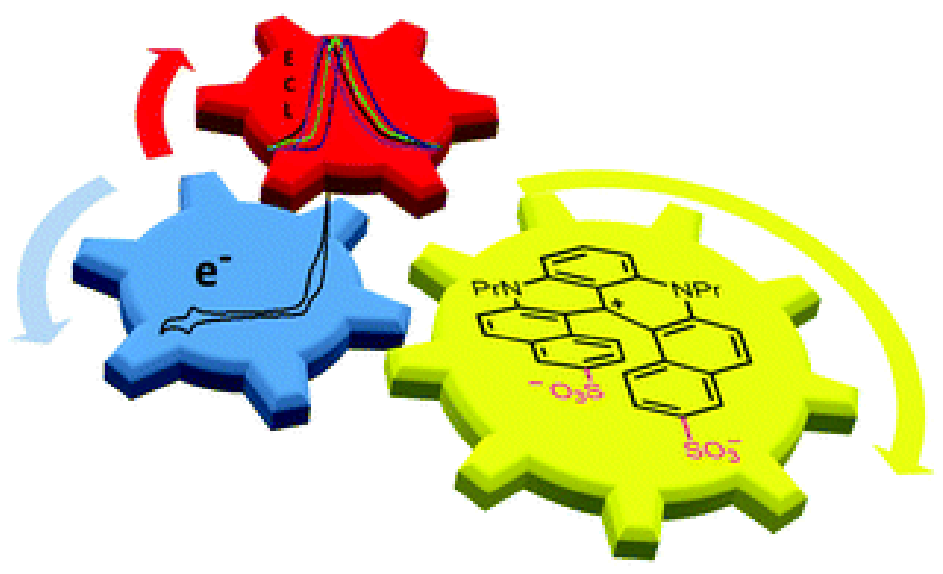

Abstract. A series of water-soluble helicene dyes generating intense electrochemiluminescence (ECL) signal in physiological conditions is reported. Those species were prepared using diaza [4] and [6]helicenes as structural cores modified with sulfonate groups in various positions. Such groups improve their water solubility and induce a red-shifted emission. Efficient ECL up to the near-infrared is achieved in water, demonstrating a viable strategy for the design of new near-infrared ECL dyes for bioassays and microscopy. 
Electrochemiluminescence (ECL) is a special case of chemiluminescence where light emission by the excited state of a luminophore is initiated by an electrochemical reaction. ${ }^{1,2}$ The electrogenerated species, which involve classically a luminophore and a sacrificial coreactant species undergo highenergy electron-transfer reactions in solution to give excited states. Nowadays, ECL is an ultrasensitive and powerful analytical method, which is on the market for clinical diagnostic. In water, the most employed ECL system is composed of tris(2,2'-bipyridyl) ruthenium(II) luminophore, noted $\left[\mathrm{Ru}(\mathrm{bpy})_{3}\right]^{2+}$, and tri-n-propylamine (TPA) coreactant. ${ }^{1,3} \mathrm{ECL}$ is a very active field of research with a special focus on the development of new ECL-active dyes and original analytical strategies in aqueous media. ${ }^{4-7}$ In that context, ruthenium and iridium complexes remain attractive despite their extremely low luminescence efficiencies and short excited state lifetimes in near-infrared region. ${ }^{8-11}$ On the other hand, organic dyes offer a wide chemical diversity with highly tunable photophysical and electrochemical characteristics. ${ }^{12-15}$ The electronic characterization of a new family of dyes featuring a helical geometry was reported recently. ${ }^{16,17}$ The chromophores are configurationally stable cationic helicenes that bear structural analogy to both triarylcarbenium ions and classical carbo- or heterohelicenes. ${ }^{18}$ In addition, these dyes feature tunable electronic and optical properties depending on the nature of the bridging heteroatoms as well as the presence of pendant functional groups. ${ }^{16}$ Also, they are ECL-active in aprotic solvents such as acetonitrile with high ECL yield. ${ }^{19}$ Various regioselective functionalizations of the helicene core can be readily achieved leading to a greater chemical diversity as well as water solubility. ${ }^{16,} 17$ Recently, we reported self-enhanced multicolor ECL using a water-soluble diaza [4]helicene bearing a tertiary dimethylamino-terminated group. ${ }^{20}$ Aside those helicene luminophores, very efficient organic ECL dyes have been designed and reported in organic media. ${ }^{13-15,} 21$ However, a major challenge is to obtain such bright organic ECL emitters operating in physiological conditions (i.e. in aqueous buffer at $\mathrm{pH} 7.4$ where bioassays and cell microscopy are relevant), especially in the near-infrared region ${ }^{11,22}$ due in part to strong nonradiative processes as governed by the energy gap law. ${ }^{23}$ Indeed, this spectral domain is particularly attractive for

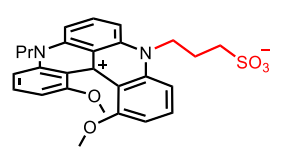

[4]-C3-Sulfo

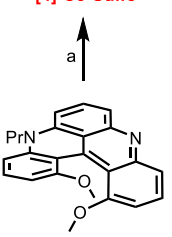

[4]quinacridine

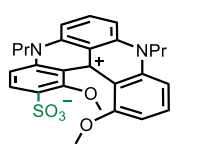

[4]-monoSulfo

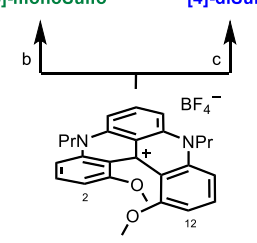

[4] helicene
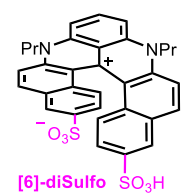

$\mathrm{d} \uparrow$

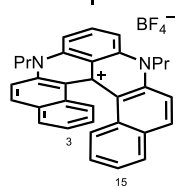

[6]helicene
Scheme 1 Structure and preparation of water-soluble helicene derivatives. Experimental conditions: (a) 1,3-propanesultone (10 equiv), DIPEA (15 equiv), $\mathrm{CH}_{3} \mathrm{CN}$, reflux, $16 \mathrm{~h}$ ( $94 \%$ yield), (b) $\mathrm{H}_{2} \mathrm{SO}_{4}$ (18 equiv), PPA, $60{ }^{\circ} \mathrm{C}, 1 \mathrm{~h}$ ( $57 \%$ yield), (c) $\mathrm{H}_{2} \mathrm{SO}_{4}$ (90 equiv), PPA, $80^{\circ} \mathrm{C}$, $2 \mathrm{~h}\left(61 \%\right.$ yield), (d) $\mathrm{H}_{2} \mathrm{SO}_{4}$ (187 equiv), $20{ }^{\circ} \mathrm{C}, 48 \mathrm{~h}$ (63\% yield). DIPEA = diisopropylethylamine, PPA = polyphosphoric acid. biological ECL applications such as cell and tissue microscopy and sensing since it enables lower background interference and longer penetration depth into biological tissues. ${ }^{24}$

Herein, we report the successful functionalization of diaza heli-cenes with either one or two sulfonate groups at different aromatic or alkyl positions affording suitable electrooptical properties for aqueous ECL (Scheme 1). Four new molecules exhibiting either [4] or [6]helicene geometries were characterized by electronic absorption, fluorescence and electrochemistry. All molecules were found to be ECL-active in the presence of TPA in phosphate-buffered saline (PBS). They display an ECL wavelength falling in the red to near-infrared region with a good ECL yield.

To achieve solubility in water, the introduction of polar groups was targeted, and sulfonate groups were selected. Two strategies were thus foreseen (Scheme 1). The sulfonate group(s) could be introduced on a terminus of a pendant aliphatic side chain ([4]-C3-Sulfo). Alternatively, those functional groups could be added to the periphery of the helicene cores via a late-stage functionalization strategy ([4]monoSulfo, [4]-diSulfo and [6]-diSulfo). In a general fashion, cationic [4]helicenes are prepared in a single step from the corresponding hexamethoxy triaryl carbenium ion through successive nucleophilic aromatic substitutions with primary amines. ${ }^{25}, 26$ Recently, the procedure was adapted for the synthesis of $\mathrm{pH}$-sensitive [4] quinacridine. ${ }^{27}$ The presence of the $\mathrm{N}$-atom is advantageous for a derivatization by nucleophilic substitution. In the present case, alkylation of [4]quinacridine with 1,3-propanesultone afforded [4]-C3-Sulfo in 94\% yield and single crystals suitable for diffraction analysis were obtained (see ESI). Although being cationic, [4] and [6] helicenes are electron-rich species. ${ }^{16,} 17$ In fact, these moieties react with electrophiles and, in strongly acidic reaction mixtures, they provide derivatives functionalized regioselectively at position 2 and/or 12 and 3 and/or 15, of [4] and [6]helicenes, respectively (Scheme 1).28 Practically, treatment of [4] helicene with $\mathrm{H}_{2} \mathrm{SO}_{4}$ in polyphosphoric acid (PPA) at $60^{\circ} \mathrm{C}$ for $1 \mathrm{~h}$ led to the formation of [4]-monoSulfo in $57 \%$ yield. Conducting this reaction at $80^{\circ} \mathrm{C}$ for $2 \mathrm{~h}$ instead led to the preferential formation of [4]-diSulfo in $61 \%$ yield. Finally, stirring [6] helicene in conc. $\mathrm{H}_{2} \mathrm{SO}_{4}$ for $48 \mathrm{~h}$ at $20{ }^{\circ} \mathrm{C}$ led to the clean formation of [6]-diSulfo isolated as the bis(2-ethylhexyl)ammonium salt in $63 \%$ yield. ${ }^{29}$

The electronic absorption spectra of the newly prepared chromophores were recorded in aqueous $0.1 \mathrm{M}$ PBS buffer ( $\mathrm{pH}$ 7.4) in the $450-800 \mathrm{~nm}$ range (Fig. 1). The four derivatives exhibit absorption in the visible domain with maximum wavelength ranging from $615 \mathrm{~nm}$ for [4]-C3-Sulfo and [6]-diSulfo to $648 \mathrm{~nm}$ for [4]-diSulfo derivatives (Table 1). The [4]-monoSulfo absorption band is centered on a maximum peaking at $632 \mathrm{~nm}$. As previously described, the functionalization of the side chain of [4]helicene ([4]-C3-Sulfo) and at positions 3 and 15 of [6]helicene ([6]-diSulfo) does not influence the optical properties, which is in stark contrast to the functionalization of [4]helicene at position(s) 2 and/or 12 ([4]monoSulfo, [4]-diSulfo) that can induce a strong modulation of the electronic properties. ${ }^{28}$ The solubility of the derivatives in aqueous medium was further investigated by UV-vis absorption from $10^{-3}$ to $10^{-6} \mathrm{M}$ concentration (see ESI). In PBS, the sulfonate 


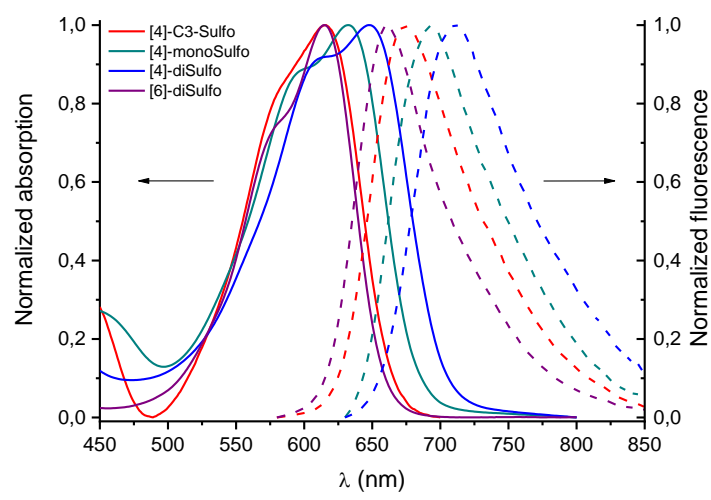

Fig. 1 Normalized absorption (plain lines) and fluorescence (dashed lines) spectra recorded in $0.1 \mathrm{M}$ PBS.

groups are deprotonated. As depicted with the case of [4]-C3Sulfo, the introduction of the sulfonate group on the side chain is not sufficient to allow a perfect solubility in PBS and the extinction coefficient is found to be varying considerably, from 500 to $4700 \mathrm{M}^{-1} \mathrm{~cm}^{-1}$, going from ca. $10^{-3}$ to $2 \times 10^{-6} \mathrm{M}$ (Figs. S16S17). On the contrary, direct functionalization of the outer rim of the helicenes revealed to be beneficial for water solubility (Figs. S18-S23). Introduction of one sulfonate group allowed the [4]-monoSulfo to be soluble up to $5 \times 10^{-5} \mathrm{M}$ in $0.1 \mathrm{M}$ PBS. With two sulfonate groups, [4]-diSulfo and [6]-diSulfo are soluble in PBS for concentrations inferior to $10^{-3} \mathrm{M}$ and $5 \times 10^{-4} \mathrm{M}$, respectively.

The photoluminescence properties were also characterized in aqueous solution by recording fluorescence spectra (Fig. 1). The spectra reveal typical large emission bands for the diaza helicenes with a full-width half-maximum value between $75 \mathrm{~nm}$ ([6]-diSulfo) and $95 \mathrm{~nm}$ ([4]helicene derivatives). The fluorescence maximum wavelength is observed in the red to near-infrared region (661 nm up to 710 $\mathrm{nm}$ ). The Stokes shift value is at least $46 \mathrm{~nm}$ and rises up to 61 $62 \mathrm{~nm}$ for the more bathochromic emitters ([4]-monoSulfo and [4]-diSulfo. Again the emission properties of [4]-C3-Sulfo and [6]-diSulfo are similar to that of non-functionalized [4] and [6]helicene whereas noticeable bathochromic shifts are observed for [4]-monoSulfo and to a larger extend for [4]diSulfo. The highest fluorescence quantum yield is measured for compound [6]-diSulfo $\left(\Phi_{F L}=6.8 \%\right)$ whereas the three other dyes exhibit weaker emission ranging from $0.6 \%$ to $2.8 \%$ (Table 1). The non-sulfonated analogues [4] and [6] helicenes showed a similar photophysical behavior in acetonitrile. Indeed, in organic media, the quantum yield of [6]helicene was $\sim 4$ times larger than the one from [4] helicene. ${ }^{19}$

The electrochemical properties of the diaza helicenes were investigated by cyclic voltammetry (CV) and/or differential pulse voltammetry (DPV) depending on the intrinsic solubility of each derivative in water. A representative CV recorded for [4]diSulfo, which is the only compound fully soluble at a concentration of $10^{-3} \mathrm{M}$ (vide supra) is provided in Fig. 2. A quasi-reversible reduction is monitored at $-0.71 \mathrm{~V}$ with a peak separation of about $100 \mathrm{mV}$. It is assigned to a mono-electronic reduction of the helicene cation core. Considering the stability of the reduced form as evidenced by a ratio of cathodic/anodic Table. 1 Photophysical, electrochemical and ECL data recorded in $0.1 \mathrm{M}$ PBS.

\begin{tabular}{|c|c|c|c|c|c|c|c|c|}
\hline & \multicolumn{2}{|c|}{$\begin{array}{l}\text { Electroche } \\
\text { mistry }^{a}\end{array}$} & \multicolumn{2}{|c|}{ Absorption } & \multicolumn{2}{|c|}{$\begin{array}{l}\text { Fluoresce } \\
\text { nce }\end{array}$} & \multicolumn{2}{|c|}{ ECL } \\
\hline dYE & $\begin{array}{r}E_{o} \\
x / V\end{array}$ & $\begin{array}{l}E_{r e d} \\
/ V\end{array}$ & $\begin{array}{r}\lambda \\
/ \mathrm{nm}\end{array}$ & $\begin{array}{l}\varepsilon / \mathrm{M}^{-1} \\
\mathrm{~cm}^{-1}\end{array}$ & $\begin{array}{c}\lambda_{F L} / \\
\mathrm{nm}\end{array}$ & $\begin{array}{r}\Phi \\
F L\end{array}$ & $\begin{array}{c}\lambda_{E C L} \\
/ \mathbf{n m}\end{array}$ & \begin{tabular}{|r|}
$\boldsymbol{\phi}$ \\
$E C L^{\mathrm{b}}$
\end{tabular} \\
\hline \begin{tabular}{|l} 
[4]-C3- \\
Sulfo
\end{tabular} & 13 & $\begin{array}{r}- \\
0.94\end{array}$ & $\begin{array}{r}6 \\
15\end{array}$ & 4700 & 672 & $\begin{array}{r}2 . \\
8 \%\end{array}$ & 671 & \begin{tabular}{r|}
3 \\
$3.9 \%$
\end{tabular} \\
\hline $\begin{array}{c}\text { [4]- } \\
\text { monoSulfo }\end{array}$ & 17 & $\begin{array}{r}- \\
0.83\end{array}$ & $\begin{array}{l}{ }^{6} \\
32\end{array}$ & 3900 & 693 & $\begin{array}{r}1 . \\
3 \%\end{array}$ & 688 & $\begin{array}{r}2 \\
1.7 \%\end{array}$ \\
\hline $\begin{array}{r}\text { [4]- } \\
\text { diSulfo }\end{array}$ & 29 & $\begin{array}{r}- \\
0.71\end{array}$ & $\begin{array}{r}6 \\
48\end{array}$ & 4800 & 710 & $\begin{array}{r}0 . \\
6 \%\end{array}$ & 708 & $\begin{array}{r}5 . \\
4 \%\end{array}$ \\
\hline $\begin{array}{r}\text { [6]- } \\
\text { diSulfo }\end{array}$ & 13 & $\begin{array}{r}- \\
0.84\end{array}$ & $\begin{array}{r}6 \\
15\end{array}$ & 13500 & 661 & $\begin{array}{r}6 . \\
8 \%\end{array}$ & 661 & $\begin{array}{r}1 \\
9.6 \%\end{array}$ \\
\hline
\end{tabular}

${ }^{a} E_{o x}(\mathrm{~V})$ and $\mathrm{E}_{\text {red }}(\mathrm{V})$ vs. $\mathrm{Ag} / \mathrm{AgCl}$ refer to the peak potentials measured by DPV or CV for mono- and di-sulfonated derivatives, respectively. ${ }^{b}$ The values have been measured with respect to $\left[\mathrm{Ru}(\mathrm{bpy})_{3}\right]^{2+}$ using $0.05 \mathrm{M}$ TPA in the same conditions (see ESI).

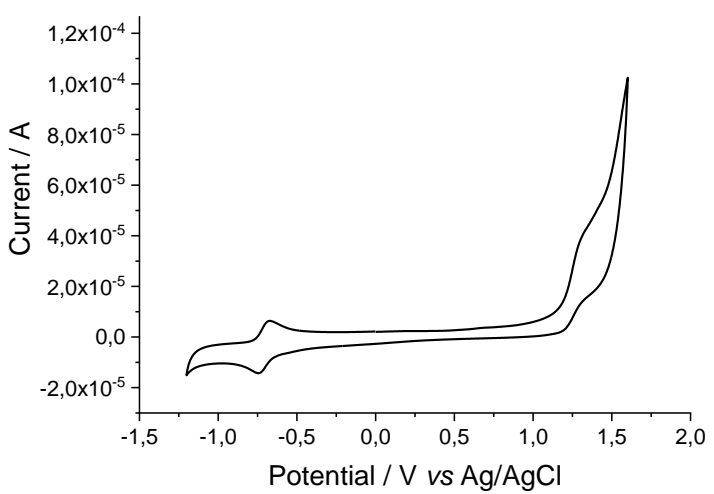

Fig. $2 \mathrm{CV}$ of $10^{-3} \mathrm{M}$ [4]-diSulfo in $0.1 \mathrm{M}$ PBS degassed for 5 minutes. Scan rate $0.1 \mathrm{~V} \mathrm{~s}^{-1}$.

peak currents of 0.92 , it offers the opportunity to explore its cathodic ECL behavior in future works. On the contrary, the oxidation process is not reversible at the time scale of the $\mathrm{CV}$ with an irreversible peak at $1.29 \mathrm{~V}$. This anodic behavior in water contrasts from the oxidation of diaza helicenes monitored in an aprotic solvent, which is usually reversible. ${ }^{19}$ However, this is not surprising since this oxidation corresponds to the formation of a dication radical core that is likely to be rather unstable in aqueous phase. CV of [6]-diSulfo (Fig. S24) shows a relatively similar electrochemical behavior as [4]diSulfo. But the irreversible oxidation occurs at less positive potential (vide infra) and the reduction process is less reversible.

The mono-sulfonated derivatives that were not soluble enough to be studied by CV were then characterized by DPV in $0.1 \mathrm{M}$ PBS at a concentration of $2 \times 10^{-5} \mathrm{M}$ (Fig. S25-S26). At this concentration, the mono-electronic reduction of [4]monoSulfo is observed at $-0.83 \mathrm{~V}$. On the other hand, the oxidation pointing at $1.17 \mathrm{~V}$ is slightly superimposed with water oxidation but still remains clearly visible by comparison to DPV recorded only in the presence of the supporting electrolyte. [4]C3-Sulfo is the only compound where the sulfonate group was introduced far apart from the helicene cation core, by modification of one of the lateral propyl chain. This diaza [4] helicene is the easiest to oxidize $\left(E_{o x}=1.13 \mathrm{~V}\right)$ whereas it is the hardest to be reduced $\left(E_{\text {red }}=-0.94 \mathrm{~V}\right)$. By comparison, the introduction of the sulfonate directly on the core like in [4]monoSulfo results in an easier reduction at $-0.83 \mathrm{~V}$. This could 
be ascribed to the presence of the electron-withdrawing group, which lower the electron density of the helicene core. The carbocation can accept more easily an electron, resulting in a less negative reduction potential. When comparing the [4]diSulfo with [6]-diSulfo, the latter is easier to oxidize ( $E_{o x}=1.13$ versus $E_{o x}=1.29 \mathrm{~V}$ for [6]-diSulfo and [4]-diSulfo, respectively) meaning that the charge of the dication core radical is more stabilized in the most extended [6]helicene structure. In acetonitrile, the oxidation and reduction reactions of [4] and [6]helicenes showed a reversible behavior with very similar potential values. ${ }^{19}$

The ECL capability in water was evaluated in oxidation, which is the main mechanistic pathway in aqueous solution. For that, $0.05 \mathrm{M}$ TPA was employed as a sacrificial coreactant. Typically, the potential is scanned towards positive values until the coreactant and the dye are oxidized (Fig. S27). The oxidation of TPA generates a radical cation $\left(\mathrm{TPA}^{\bullet+}\right)$, which dissociates spontaneously by losing a proton. The corresponding neutral radical (TPA ${ }^{\circ}$ ) is a strong reducer that is characterized by a rather negative potential $E_{\text {red }} \sim-1.7 \mathrm{~V}$ vs. $\mathrm{Ag} / \mathrm{AgCl} .{ }^{10,30} \mathrm{Fig}$. S27 shows a first small ECL peak appearing before the oxidation of the helicenes. The corresponding mechanistic pathway can be described by the so-called "revisited route" detailed in ESI (Eq. S1-S5). The predominant ECL peak occurs at the potentials where the dyes are oxidized and involves a very exergonic electron-transfer reaction between a strong oxidant (helicene radical) and a strong reducer (TPA ) that are formed simultaneously in the vicinity of the electrode (see ESI). The free enthalpy of reaction $\Delta r G^{\circ}$ of the corresponding electrontransfer process can be easily estimated by the difference of redox potentials $\left(E_{o x}\left(\right.\right.$ helicene) $-E_{\text {red }}\left(\operatorname{TPA}^{\circ}\right)$ ), leading to an exergonic situation for all four compounds. The corresponding $\Delta r G^{\circ}$ values span from 2.83 to $2.99 \mathrm{eV}$ (without taking into account the entropic contribution (typically, $0.1 \mathrm{eV}$ ) that remains constant and negligible compared to the enthalpic term). In all cases, the enthalpy released by the redox reaction is much higher than the energy corresponding to the wavelength of emission that can be calculated according to the formula $\left(E_{F L}\right.$ (in eV) $=1239.81 / \lambda_{F L}$ (in $\mathrm{nm}$ ). These calculated values of $E_{F L}$ range from 1.75 to $1.88 \mathrm{eV}$ confirming that all four molecules should be indeed ECL-active. The ECL spectra recorded by applying a potential of $1.4 \mathrm{~V}$ are gathered in Fig. S28. It is noteworthy that it is the first time that this series of molecules are investigated in aqueous media revealing an intense ECL signal. The maximum value for ECL was compared to fluorescence (Table 1) showing that the same excited state is involved with $\lambda_{E C L}$ values very close to $\lambda_{F L} \pm 5 \mathrm{~nm}$.

The ECL efficiency $\Phi_{E C L}$ was estimated with respect to $\left[\mathrm{Ru}(\mathrm{bpy})_{3}\right]^{2+}$ in the same experimental conditions (Fig. S27). Significant $\Phi_{E C L}$ values were found from $5.4 \%$ for [4]-diSulfo up to $33.9 \%$ for [4]-C3-Sulfo derivative. The lowest ECL yield is obtained for the compound that exhibits the highest oxidation potential but that suffers from a poor fluorescence quantum yield $\left(\Phi_{F L}=0.6 \%\right)$. On the other hand, the brightest $E C L$ emitter is [4]-C3-Sulfo. It illustrates the influence of the position of the sulfonate group(s) on the ECL emission. $E C L$ is brighter when the sulfonate group is located further from the diaza core. In PBS, $\Phi_{E C L}$ of [4]-C3-Sulfo is larger to that of [6]-diSulfo despite a similar oxidation potential $\left(E_{o x}=1.13 \mathrm{~V}\right)$. The behavior was similar in acetonitrile where $\Phi_{E C L}$ value of [4] helicene was 2.3 times greater than [6]helicene using also TPA. ${ }^{19}$ But, contrary to the aqueous media, the situation was different since the oxidized radicals of both [4] and [6]helicenes were stable in $\mathrm{CH}_{3} \mathrm{CN}$. In PBS, the brightest ECL dye (i.e. [4]-C3-Sulfo) emitting at $671 \mathrm{~nm}$ exhibits a lower quantum yield in comparison to [6]diSulfo, which emits at $661 \mathrm{~nm}$ (Table 1). The variations of quantum yield (Table 1) are coherent with the energy gap law, which implies that the rate of nonradiative process increases with the longer emission wavelengths. ${ }^{23}$ Considering the energetics of the ECL process, both dyes have the same free enthalpy of reaction with $\operatorname{TPA}^{\circ}$. Since the lower energy of the excited state is just about $0.03 \mathrm{eV}$ due to a $10 \mathrm{~nm}$ red-shift in $\lambda_{E C L}$, this very small difference of exergonicity $(0.03 \mathrm{eV})$ of the reaction generating the excited state cannot explain the observed difference in $\Phi_{E C L}$. On the other hand, the stability of the electrogenerated species is a crucial parameter governing the ECL efficiency. ${ }^{31,32}$ Therefore, we can hypothesize that this higher ECL efficiency of [4]-C3-Sulfo is related to a better stability of the oxidized form.

Herein, the synthesis of a new series of water-soluble diaza helicenes functionalized with either one or two sulfonate groups is reported. Consequently, these molecules are soluble in aqueous phase. The optical as well as electrochemical behavior was characterized in PBS. In brief, these dyes strongly absorb in the visible region. They emit in the red to nearinfrared region (with maxima between 661 and $710 \mathrm{~nm}$ ) and the excited state can be reached either by photo-excitation or ECL. These molecules are indeed redox-active and can be oxidized to afford the corresponding radical in water. Although such an oxidation appears to be irreversible in water, the stability of the electrogenerated species is sufficient to undergo redox chemistry with electrogenerated TPA ${ }^{\bullet}$ radical. This classic ECL pathway leads to a strong ECL emission with an ECL efficiency ranging from $5.4 \%$ up to $33.9 \%$ by comparison with $\left[\mathrm{Ru}(\mathrm{bpy})_{3}\right]^{2+}$ standard. The brightest ECL emitter was found to be the [4]-C3Sulfo derivative, which gathered a high oxidation potential with a red ECL occurring readily at $671 \mathrm{~nm}$. Finally, the [4]-diSulfo compound exhibits the highest solubility in water together with an ECL emission at $688 \mathrm{~nm}$ that is very promising for future applications such as multiplexed bioassays and ECL imaging in biorelevant samples.

\section{Conflicts of interest}

There are no conflicts to declare.

\section{Acknowledgements}

We thank A. Kapturkiewicz for helpful discussions on ECL efficiency. RD, SP, JB and JL thank the University of Geneva and the Swiss National Science Foundation for financial support (SNF 200020-172497 and 200020-184843).

\section{Notes and references}


1.Z. Liu, W. Qi and G. Xu, Chem. Soc. Rev., 2015, 44, 3117-3142.

2.L. Li, Y. Chen and J.-J. Zhu, Anal. Chem., 2017, 89, 358-371.

3.M. Hesari and Z. Ding, J. Electrochem. Soc., 2016, 163, H3116H3131.

4.S. Kudruk, E. Villani, F. Polo, S. Lamping, M. Körsgen, H. F. Arlinghaus, F. Paolucci, B. J. Ravoo, G. Valenti and F. Rizzo, Chem. Comm., 2018, 54, 4999-5002.

5.A. Zanut, A. Fiorani, S. Rebeccani, S. Kesarkar and G. Valenti, Anal. Bioanal. Chem., 2019, 411, 4375-4382.

6. S. Voci, B. Goudeau, G. Valenti, A. Lesch, M. Jović, S. Rapino, F. Paolucci, S. Arbault and N. Sojic, J. Am. Chem. Soc., 2018, 140, 14753-14760.

7. C. Ma, Y. Cao, X. Gou and J.-J. Zhu, Anal. Chem., 2020, 92, 431454.

8. M. M. Cooke, E. H. Doeven, C. F. Hogan, J. L. Adcock, G. P. McDermott, X. A. Conlan, N. W. Barnett, F. M. Pfeffer and P. S. Francis, Anal. Chim. Acta, 2009, 635, 94-101.

9. K. N. Swanick, S. Ladouceur, E. Zysman-Colman and Z. Ding Angew. Chem. Int. Ed., 2012, 51, 11079-11082.

10. B. D. Stringer, L. M. Quan, P. J. Barnard, D. J. D. Wilson and C. F. Hogan, Organometallics, 2014, 33, 4860-4872.

11. M. Majuran, G. Armendariz-Vidales, S. Carrara, M. A Haghighatbin, L. Spiccia, P. J. Barnard, G. B. Deacon, C. F. Hogan and K. L. Tuck, ChemPlusChem, 2020, 85, 346-352.

12. G. Valenti, C. Bruno, S. Rapino, A. Fiorani, E. A. Jackson, L. T. Scott, F. Paolucci and M. Marcaccio, J. Phys. Chem. C, 2010, 114, 1946719472.

13. F. Polo, F. Rizzo, M. Veiga-Gutierrez, L. De Cola and S. Quici, J. Am. Chem. Soc., 2012, 134, 15402-15409.

14. M. Hesari, S. M. Barbon, V. N. Staroverov, Z. Ding and J. B. Gilroy, Chem. Comm., 2015, 51, 3766-3769.

15. F. Rizzo, F. Polo, G. Bottaro, S. Fantacci, S. Antonello, L. Armelao, S. Quici and F. Maran, J. Am. Chem. Soc., 2017, 139, 2060-2069.

16. I. Hernández Delgado, S. Pascal, A. Wallabregue, R. Duwald, C. Besnard, L. Guénée, C. Nançoz, E. Vauthey, R. C. Tovar, J. L. Lunkley, G. Muller and J. Lacour, Chem. Sci., 2016, 7, 4685-4693.

17. J. Bosson, G. M. Labrador, S. Pascal, F.-A. Miannay, O. Yushchenko, H. Li, L. Bouffier, N. Sojic, R. C. Tovar, G. Muller, D. Jacquemin, A. D. Laurent, B. Le Guennic, E. Vauthey and J. Lacour, Chem. Eur. J., 2016, 22, 18394-18403.

18. J. Bosson, J. Gouin and J. Lacour, Chem. Soc. Rev., 2014, 43, 2824 2840.

19. H. Li, A. Wallabregue, C. Adam, G. M. Labrador, J. Bosson, L. Bouffier, J. Lacour and N. Sojic, J. Phys. Chem. C, 2017, 121, 785792.

20. S. Voci, R. Duwald, S. Grass, D. J. Hayne, L. Bouffier, P. S. Francis, J. Lacour and N. Sojic, Chem. Sci., 2020, 11, 4508-4515.

21. K. M. Omer, S.-Y. Ku, J.-Z. Cheng, S.-H. Chou, K.-T. Wong and A. J. Bard, J. Am. Chem. Soc., 2011, 133, 5492-5499.

22. R. R. Maar, R. Zhang, D. G. Stephens, Z. Ding and J. B. Gilroy, Angew. Chem. Int. Ed., 2019, 58, 1052-1056.

23. M. Bixon, J. Jortner, J. Cortes, H. Heitele and M. E. MichelBeyerle, J. Phys. Chem., 1994, 98, 7289-7299.

24. J. V. Frangioni, Curr. Opin. Chem. Biol., 2003, 7, 626-634.

25. B. W. Laursen and F. C. Krebs, Chem. Eur. J., 2001, 7, 1773-1783.

26. B. W. Laursen and F. C. Krebs, Angew. Chem. Int. Ed., 2000, 39, 3432-3434.

27. A. Wallabregue, P. Sherin, J. Guin, C. Besnard, E. Vauthey and J. Lacour, Eur. J. Org. Chem., 2014, 6431-6438.

28. R. Duwald, J. Bosson, S. Pascal, S. Grass, F. Zinna, C. Besnard, L. Di Bari, D. Jacquemin and J. Lacour, Chem. Sci., 2020, 11, 11651169.

29. U.S. Pat., No. 3,211,526, 1965.
30. W. Miao, J.-P. Choi and A. J. Bard, J. Am. Chem. Soc., 2002, 124, 14478-14485.

31. A. Kapturkiewicz, J. Nowacki and P. Borowicz, Electrochim. Acta, 2005, 50, 3395-3400.

32. I.-S. Shin, J. I. Kim, T.-H. Kwon, J.-I. Hong, J.-K. Lee and H. Kim, J. Phys. Chem. C, 2007, 111, 2280-2286. 